\title{
Accuracy of the interferon-gamma release assay for the diagnosis of tuberculous pleurisy: an updated meta-analysis
}

Caishuang Pang, Yongchun Shen, Panwen Tian, Jing Zhu, Mei Feng, Chun Wan, Fuqiang Wen

Background and objectives: The best method for diagnosing tuberculous pleurisy (TP) remains controversial. Since a growing number of publications focus on the interferongamma release assay (IGRA), we meta-analyzed the available evidence on the overall diagnostic performance of IGRA applied to pleural fluid and peripheral blood. Materials and methods: PubMed and Embase were searched for relevant English papers up to October 31, 2014. Statistical analyses were performed using Stata and Meta-DiSc. Pooled sensitivity, specificity, positive likelihood ratio (PLR), negative likelihood ratio(NLR), positive predictive value (PPV), negative predictive value (NPV) and diagnostic odds ratio (DOR) were count. Summary receiver operating characteristic curves and area under the curve (AUC) were used to summarize the overall diagnostic performance. Results: Fifteen publications met our inclusion criteria and were included inthemeta analysis. The following pooled estimates for diagnostic parameters of pleural IGRA were obtained: sensitivity, 0.82 (95\%Cl 0.79-0.85); specificity, 0.87 (95\%Cl 0.84-0.90); PLR, 4.94 (95\% Cl 2.60-9.39); NLR, 0.22 (95\% Cl 0.13-0.38); PPV, 0.91 (95\%Cl 0.85-0.96); NPV, 0.79 (95\% Cl 0.71-0.85); DOR, 28.37 (95\% Cl 10.53-76.40); and AUC, 0.91. The corresponding estimates for blood IGRA were as follows: sensitivity, $0.80(95 \% \mathrm{Cl} 0.76-0.83)$; specificity, $0.70(95 \% \mathrm{Cl} 0.65-0.75)$; PLR, 2.48 (95\%Cl 1.95-3.17); NLR, 0.30 (95\%Cl 0.24-0.37); PPV, 0.79 (95\% Cl 0.60-0.87); NPV, 0.75 (95\% Cl 0.62-0.83); DOR, 9.96(95\%Cl 6.02-16.48); and AUC, 0.89. Conclusions: This meta analysis suggested that pleural IGRA has potential for serving as a complementary method for diagnosingTP, however, its cost, high turn around time, and sub-optimal performance make it unsuitable as a stand-alone diagnostic tool. Better tests for the diagnosis of TP are required. 
2 Cai-Shuang Pangף, Yong-Chun Shenף, Pan-Wen Tianף, Jing Zhu, Mei Feng, Chun Wan, Fu-Qiang 3 Wen*

4

5 Department of Respiratory and Critical Care Medicine, West China Hospital of Sichuan University and

6 Division of Pulmonary Diseases, State Key Laboratory of Biotherapy of China.

8 "Contributed equally to this manuscript

$9 \quad{ }^{*}$ Corresponding author

10 Fuqiang Wen M.D., Ph.D

11 Department of Respiratory and Critical Care Medicine, West China Hospital of Sichuan University and

12 Division of Pulmonary Diseases, State Key Laboratory of Biotherapy of China, Chengdu 610041,

13 China.

14 E-mail: wenfuqiang.scu@gmail.com

$15 \quad$ Tel: $+86-28-85422350 \quad$ Fax: $+86-28-85582944$

16 
23 Introduction

24 Tuberculous pleurisy (TP) is the most common form of extrapulmonary tuberculosis,

25 accounting for $23 \%$ of all tuberculosis cases and $30 \%$ of cases of disease-causing

26 pleural effusion (PE) (Vidal R et al., 1986; Corbett EL et al., 2003; Valdés L et al.,

27 2003), which involves exudate containing primarily lymphocytes. Direct diagnosis of

28 TP would be the best way to avoid misdiagnosis and the resulting inappropriate

29 treatment (Lin MT et al., 2009), but this remains a challenge. Definitive diagnosis of

30 TP depends on isolating Mycobacterium tuberculosis from PE or pleural tissue.

31 Conventional methods, such as PE culture, pleural biopsy and Ziehl-Neelsen staining,

32 show poor sensitivity for detecting the limited amounts of bacteria in the PE of

33 affected patients (Escudero BC et al., 1990; Valdés L et al., 1998). Culturing PE is

34 also time-consuming. Pleural biopsy is invasive and technically difficult, so its 
35 effectiveness depends on technical skill (Pérez RE \& Jiménez CD, 2000). It may not

36 be suitable for elderly and children, individuals with underlying co-morbidities, and

37 those at high risk of bleeding. The tuberculin skin test is cross-reactive for Bacille

38 Calmette Guérin (BCG) and many non-tuberculous mycobacteria, increasing the risk

39 of misdiagnosis (Lawrence JG, 2000; Stead WW \& To T, 1987; Liebeschuetz S et al.,

40 2004). The limitations of these conventional approaches to diagnosing TP highlight

41 the need to identify new diagnostic tools.

42 The PE of patients with TP has been shown to contain significantly higher levels

43 of T lymphocytes and interferon (IFN)- $\gamma$ than peripheral blood (North RJ \& Jung YJ,

44 2004; Sharma SK et al., 2002), and the PE of these patients contains higher IFN- $\gamma$

45 levels than the PE of uninfected individuals (Yamada $\mathrm{Y}$ et al., 2001). In fact, $\mathrm{T}$

46 lymphocytes that have previously been exposed to MTB release more IFN- $\gamma$ on repeat

47 exposure. This inspired the development of a T-cell IFN- $\gamma$ release assay (IGRA),

48 which is now licensed as a blood test for diagnosis of latent tuberculosis (Lalvani A,

49 2007; Pai M, Zwerling A \& Menzies D, 2008).

50 Whether IGRA can be used to diagnose TP is controversial. A previous 
51 meta-analysis concluded that it showed poor sensitivity and specificity for this

52 purpose (Zhou Q et al., 2011). Nevertheless, a growing number of studies have

53 focused on extending the use of IGRA to the diagnosis of TP (Hooper CE, Lee YC

$54 \&$ Maskell NA, 2009). Therefore, the present meta-analysis was undertaken to

55 comprehensively assess the overall accuracy of IGRA for the diagnosis of TP.

\section{Material \& Methods}

\section{Search strategy and study selection}

58 PubMed and Embase were searched for articles published before October 31, 2014. The following

59 search terms were used: "pleural effusion/pleural fluid, pleurisy/pleuritis AND elispot, OR quantiferon,

60 OR interferon-gamma assays, OR interferon-gamma release assays, OR t cell assays". The related-

61 articles function was also used, and reference lists in relevant articles were searched manually.

62 Studies were included in our meta-analysis if they (1) used IGRA testing for the diagnosis of

63 tuberculous pleurisy (2) reported sufficient data to calculate true positive, false positive, false negative,

64 and true negative of IGRA for the diagnosis of TP, and (3) constituted original research published in

65 English. Studies available only as abstracts were excluded.

\section{Data extraction and quality assessment}

67 Two reviewers independently checked all potentially relevant studies, and disagreements were resolved 
by consensus. Data were collected from each study, including first author, year of publication, country, participant characteristics, IGRA method, samples, cut-off values, sensitivity, specificity and methodological quality. For each study we constructed $2 \times 2$ contingency tables in which we calculated true positive, false positive, false negative, and true negative rates.

The methodological quality of the studies was assessed using the 14-items Quality Assessment for Studies of Diagnostic Accuracy (QUADAS) guidelines (Whiting P et al., 2003). When a criterion was fulfilled, a score of 1 was given, 0 if a criterion was unclear, and -1 if a criterion was not achieved. This evaluation instrument rates studies on a quality scale of up to 14 points.

\section{Statistical analyses}

Standard methods recommended for meta-analyses of diagnostic test evaluations (Devillé WL et al., 2002) were used. Stata 12.0 and Meta-DiSc 1.4 were used for statistical analysis. The following accuracy measures were calculated for each study: sensitivity, specificity, positive likelihood ratio (PLR), negative likelihood ratio(NLR), positive predictive value (PPV), negative predictive value (NPV) and diagnostic odds ratio (DOR). Summary receiver operating characteristic (SROC) curves and area under the curve (AUC) were also calculated (Moses LE, Shapiro D \& Littenberg B, 1993; Irwig L et al., 1995; Vamvakas EC, 1998). Heterogeneity across studies was detected using chi-square and Fisher's exact tests. We planned to use a random-effects model to synthesize data if heterogeneity was present $\left(\mathrm{P}<0.05\right.$ and $\left.\mathrm{I}^{2}>50 \%\right)$ (Shen $\mathrm{YC}$ et al., 2012). Based on this rule, pooled average sensitivity, specificity and other diagnostic parameters of pleural and blood IGRA were calculated using, respectively, a random-effects model and a fixed-effects model (Irwig L et al., 1995; Vamvakas 
88 EC, 1998). Potential presence of publication bias was tested using funnel plots and the Egger's test. All 89 statistical tests were two-sided, and the threshold of significance was set at $\mathrm{P}<0.05$.

90 Results

\section{Study inclusion and characteristics}

92 Study identification and selection were outlined in Fig. 1. In the end, 15 publications

93 of IGRA to diagnose patients with TP were eligible for inclusion (Wilkinson KA et al.,

94 2005; Ariga H et al., 2007; Losi M et al., 2007; Baba K et al., 2008; Chegou NN et al.,

95 2008; Dheda K et al., 2009; Lee LN et al., 2009; Keng LT et al., 2013; Ates G et al.,

96 2011; Eldin EN et al., 2012; Kang JY et al., 2012; Liu F et al., 2013; Liao MF et al.,

97 2014; Chung JH et al., 2011; Gao Y et al., 2012). In the studies by Dheda et al. (2009)

98 and Kang et al. (2012), IGRA was performed in two formats: as an enzyme-linked

99 immunosorbent spot (ELISPOT) assay, and as an enzyme-linked immunosorbent

100 assay (ELISA). Thus each of these publications was treated as two independent

101 studies in our meta-analysis, giving 17 studies in our meta-analysis altogether.

102 ELISPOT was used in seven studies (Wilkinson KA et al., 2005; Losi M et al.,

103 2007; Dheda K et al., 2009; Lee LN et al., 2009; Kang JY et al., 2012; Liu F et al., 
104 2013; Liao MF et al., 2014), while ELISA was used in the remaining 10 studies

105 (Ariga $\mathrm{H}$ et al., 2007; Baba K et al., 2008; Chegou NN et al., 2008; Dheda K et al.,

106 2009; Keng LT et al., 2013; Ates G et al., 2011; Eldin EN et al., 2012; Kang JY et al.,

107 2012; Chung JH et al., 2011; Gao Y et al., 2012). Across all studies, 17 analyses of PE

108 (Wilkinson KA et al., 2005; Ariga H et al., 2007; Losi M et al., 2007; Baba K et al.,

109 2008; Chegou NN et al., 2008; Dheda K et al., 2009; Lee LN et al., 2009; Keng LT et

110 al., 2013; Ates G et al., 2011; Eldin EN et al., 2012; Kang JY et al., 2012; Liu F et al.,

111 2013; Liao MF et al., 2014; Gao Y et al., 2012). and 14 analyses of blood (Wilkinson

112 KA et al., 2005; Ariga Het al., 2007; Losi M et al., 2007; Baba K et al., 2008; Chegou

113 NN et al., 2008; Dheda K et al., 2009; Lee LN et al., 2009; Ates G et al., 2011; Eldin

114 EN et al., 2012; Kang JY et al., 2012; Liu F et al., 2013; Liao MF et al., 2014; Chung

115 JH et al., 2011) were conducted. Ten studies were conducted in Asia, five in Africa,

116 and two in Europe. Key characteristics of included studies, along with QUADAS

117 score, were shown in Table 1.

118 Nine studies included at least 60 patients (Ariga H et al., 2007; Chegou NN et al.,

119 2008; Dheda K et al., 2009; Keng LT et al., 2013; Ates G et al., 2011; Liu F et al., 
121 size in the 17 analyses of pleural IGRA was 76 (range 18-332), involving a total of

122806 patients with TP and 482 without TP. Mean sample size in the 14 analyses of

123 blood IGRA was 80 (range 34-332), involving altogether 730 patients with TP and

124383 without TP.

\section{Diagnostic accuracy}

126 In the 17 analyses of pleural IGRA, diagnostic sensitivity ranged from 0.44 to 1.0 (Fig. 2); pooled 127 sensitivity was $0.82\left(95 \%\right.$ CI $\left.0.79-0.85 ; \mathrm{I}^{2}=92 \%\right)$. Specificity ranged from 0.5 to 1.0 , and pooled 128 specificity was $0.87\left(95 \%\right.$ CI $\left.0.84-0.90 ; \mathrm{I}^{2}=82.5 \%\right)$. Other pooled estimates of diagnostic parameters

129 were as follows: PLR, 4.94 (95\% CI 2.60-9.39); NLR, 0.22 (95\% CI 0.13-0.38); PPV, 0.91 (95\% CI

130 0.85-0.96); NPV, 0.79 (95\% CI 0.71-0.85); and DOR, 28.37 (95\% CI 10.53-76.4). Chi-square values

131 for these parameters suggested considerable heterogeneity among studies (Table 2): sensitivity, 199.86;

132 specificity, 91.18; PLR, 129.36; NLR, 180.23; PPV, 132; NPV, 157; and DOR, 81.01 (all P < 0.001).

133 For 14 analyses of blood IGRA, diagnostic sensitivity ranged from 0.71 to 0.93 (Fig. 2), and 134 specificity ranged from 0.56 to 1.0 . Pooled estimates of the other diagnostic parameters were as 135 follows: sensitivity, $0.8\left(95 \%\right.$ CI 0.76-0.83; $\left.\mathrm{I}^{2}=31.9 \%\right)$; specificity, 0.7 (95\% CI 0.65-0.75; $\mathrm{I}^{2}=$ 136 54.4\%); PLR, 2.48 (95\% CI 1.95-3.17); NLR, 0.3 (95\% CI 0.24-0.37); PPV, 0.79 (95\% CI 0.60-0.87);

137 NPV, 0.75 (95\% CI 0.62-0.83); and DOR, 9.96 (95\% CI 6.02-16.48). Chi-square values for most of 
138 these parameters indicated no significant heterogeneity among studies (Table 2): sensitivity, $19.09(\mathrm{P}=$ 139 0.12); NLR, $18.02(\mathrm{P}=0.16) ; \mathrm{PPV}, 4.27(\mathrm{P}=0.09)$; and NPV, $4.54(\mathrm{P}=0.07)$. In contrast, chi-square 140 values indicated significant heterogeneity for specificity (28.52), PLR (26.57) and DOR (24.44) (all P $141<0.05)$.

142 This meta-analysis involved two different types of commercially available assays: ELISPOT and 143 ELISA. The ELISPOT assay, such as the T-SPOT-TB, involves sensitizing T cells to specific $M$. 144 tuberculosis antigens, such as the early secreted antigenic target 6 (ESAT-6) and culture filtrate protein

14510 (CFP-10), and then measuring the IFN- $\gamma$ subsequently released. ELISA, such as Quanti-FERON-TB 146 Gold (QFN-G) or the third-generation 'In-Tube' (QFN-IT), measures the release of INF- $\gamma$ into whole

147 blood or PE after stimulation by ESAT-6 and CFP-10. Comparison of overall diagnostic values for

148 ELISPOT and ELISA did not allow a conclusion about which assay type was superior (Table 2).

149 We assessed the overall diagnostic performance by calculating SROC curves and the corresponding

150 AUC. The SROC curve for pleural IGRA was not positioned near the desirable upper left corner, and

151 the point where sensitivity equals specificity (Q) was 0.84 ; the optimum AUC was 0.91 (Fig. 3A). The

152 corresponding SROC curve for blood IGRA showed Q of 0.77 and AUC of 0.84 (Fig. 3B). Although

153 neither the pleural or blood AUC was entirely satisfactory, this summary analysis suggests that pleural

154 IGRA shows much better diagnostic performance than blood IGRA.

\section{Multiple regression analysis and publication bias}

156 The quality of the 17 studies in this meta-analysis varied considerably, with only 
157 five studies earning high QUADAS scores ( $\geq 11$; Table 1). These scores were used in

158 a meta-regression analysis to assess the effect of study quality on the relative DOR

159 (RDOR) of IGRA for the diagnosis of TP (Table 3). Higher- and lower-quality studies

160 did not differ significantly in RDOR for either pleural or blood IGRA (Table 3). Seven

161 studies were performed in areas with a low tuberculosis incidence (Wilkinson KA et

162 al., 2005; Ariga H et al., 2007; Losi M et al., 2007; Keng LT et al., 2013; Ates G et al.,

163 2011; Eldin EN et al., 2012; Kang JY et al., 2012) and 10 studies (eight publications)

164 were performed in areas with a high tuberculosis incidence (Baba K et al., 2008;

165 Chegou NN et al., 2008; Dheda K et al., 2009; Lee LN et al., 2009; Liu F et al., 2013;

166 Liao MF et al., 2014; Chung JH et al., 2011; Gao Y et al., 2012). Diagnostic accuracy

167 of pleural IGRA depended significantly only on assay method (ELISPOT vs ELISA,

$168 \mathrm{P}=0.023)$, but not on study quality or tuberculosis incidence. Diagnostic accuracy of

169 blood IGRA depended significantly on both assay method and tuberculosis incidence.

170 Results of the RDOR analysis were shown in Table 3.

171 Publication bias was analyzed by using funnel plots and the Egger's test. Since the funnel plots for

172 publication bias showed asymmetry (Fig. 4), Egger's tests were performed, which confirmed significant 
173 risk of publication bias in the meta-analyses for both blood IGRA and pleural IGRA (both $\mathrm{P}<0.001$ ).

174

175

176

177

178

179

180

181

182

183

184

185

186

187

188

189

190

191

192

\section{Discussion}

IGRA has an advantage over conventional methods of diagnosing M. tuberculosis infection, because it is based on specific antigens, such as ESAT-6 and CFP-10, that are absent from BCG and most environmental mycobacteria. Whether this assay is suitable for diagnosing TP is controversial. In fact, Zhou Q et al. (2011) conducted a meta-analysis to analyze the diagnostic role of IGRA for TP.

According to his inclusion criteria, only seven publications were included. Several years have passed, and some new studies have been added, so we conducted this updated meta-analysis. Our metaanalysis summarizes the available evidence on this question in an effort to provide guidance for TP diagnosis. Our results showed that the pooled sensitivities of pleural and blood IGRA were 0.82 and 0.80 , respectively, and the corresponding specificities were 0.87 and 0.70 . These findings, coupled with the relatively low AUC values representing overall performance, suggest that IGRA has some usefulness for diagnosing TP, but that it should be interpreted only in conjunction with conventional tests or clinical signs. Positive results from IGRA may be helpful for confirming TP, but the relatively low sensitivity makes it vulnerable to generating false negatives. Significant heterogeneity was found in sensitivity, specificity, PLR, NLR, DOR for pleural IGRA, and specificity, PLR, DOR for blood IGRA. Five studies had a higher QUADAS score $(\geq 11)$. There was no significant difference between higher-quality studies and lower-quality ones.

We assessed pleural and blood IGRAs using SROC curves and DOR tests, both of which combine sensitivity and specificity. SROC curves, which are unlikely to be affected by a diagnostic threshold 
193 effect (Jones CM \& Athanasiou T, 2005), showed an optimum cut-off of 0.84 for pleural IGRA and

1940.77 for blood IGRA, while the corresponding AUCs were 0.91 and 0.84 , suggesting less than fully

195 satisfactory overall accuracy. The DOR of a test is the ratio of the odds of obtaining a positive test

196 result in the disease group to the odds of obtaining a positive test result in the no-disease group (Zhou

197 Q et al., 2011). When DOR $>1$, higher values indicate better discriminatory test performance. We

198 calculated a pooled DOR of 28.37 for pleural IGRA and of 9.96 for blood IGRA, suggesting that IGRA

199 and particularly pleural IGRA may be helpful for diagnosing TP. We found higher pooled sensitivity

200 and specificity for pleural IGRA than a previous meta-analysis (Zhou Q et al., 2011), which likely

201 reflects our inclusion of more articles. Similarly we calculated a higher pooled DOR for pleural IGRA

202 (19.0, 95\% CI 4.8-75.8) than that meta-analysis did. We conclude that pleural IGRA has better

203 prospects than blood IGRA for widespread clinical implementation. This was possibly due to

204 compartmentalization of antigen-specific effector $\mathrm{T}$ cells, which could be recruited and concentrated at

205 the site of infection, such as pleural cavity. ESAT-6-specific, IFN- $\gamma$ secreting T-cells have a 15 -fold

206 concentration in PE relative to peripheral blood in patients with TP(Wilkinson KA et al., 2005).

207 Potentially more clinically meaningful than DOR and SROC, PLR and NLR are often used as

208 measures of diagnostic accuracy. PLR indicates how much the odds of a condition are increased by a

209 positive test, while NLR indicates how much they are decreased by a negative test. Larger PLR means

210 greater diagnostic accuracy, whereas a smaller NLR is better. The pooled PLR of 4.94 for pleural

211 IGRA suggests that patients with TP have a nearly five-fold greater chance of a positive test result than

212 patients without TP. Even though this PLR is larger than that reported in a previous meta-analysis 
213 (Zhou Q et al., 2011), it is still too small for clinical purposes. At the same time, we calculated a pooled

214 NLR of 0.22 for pleural IGRA, indicating that the probability that a patient with a negative result has a

$21522 \%$ chance of having TP, which is not low enough to reliably rule out false negatives. The

216 corresponding PLR and NLR for blood IGRA were even less satisfactory.

217 The pooled PPV for pleural IGRA was 0.91 , indicating that $9 \%$ of positive results may be false

218 positives. The NPV of pleural IGRA was 0.79 , suggesting a negative rate of $21 \%$. The corresponding

219 values for blood IGRA were less satisfactory. Although these PPV and NPV values are higher than

220 those reported in a recent meta-analysis (Zhou Q et al., 2011), they are still not as high as necessary for

221 reliable clinical performance.

222

Our results are consistent with the observation that pleural and blood IGRAs give a relatively high

rate of false positive test results because IGRA cannot distinguish active from latent tuberculosis

224 (Hooper CE, Lee YC \& G Maskell NA, 2009; Dheda K et al., 2009). In the present meta-analysis, we

225 found pleural IGRA to show a lower rate of false positive results than false negative results. Previous

226 studies showed IGRA, especially T-SPOT-TB, to be helpful in the diagnosis of latent tuberculosis

227 (Lalvani A, 2007; Pai M, Zwerling A \& Menzies D, 2008), while the overall accuracy of the technique

228 for diagnosing TP was lower than for diagnosing latent tuberculosis (Diel R et al., 2011) but higher

229 than for diagnosing active tuberculosis (Sester M et al., 2011). This dependence of diagnostic accuracy

230 on tuberculosis form may reflect the fact that patients with latent M. tuberculosis infection live with

231 superior immunologic function, such that smaller pathogen load can elicit an effective response to

232 tuberculosis antigen. Another explanation is significant heterogeneity among studies. A third possible 
explanation is transient exposure to non-replication persistent $M$. tuberculosis in the pleural space of

234 patients without PE.

235 Two types of IGRAs are commercially available: the ELISA-based QFT-G or QFT-IT, and the

236 ELISPOT-based T-SPOT-TB. Although both ELISPOT and ELISA measure IFN- $\gamma$ release after T cell

237 stimulation by ESAT-6 and CFP-10, ELISPOT has been reported to be more stable and sensitive

238 (Liebeschuetz S et al., 2004). Indeed, we found the sensitivity, PLR, DOR and AUC to be higher for

239 pleural ELISPOT than for pleural ELISA (Table 2). On the other hand, the specificity and NLR were

240 lower for pleural ELISPOT than for pleural ELISA. In the blood-based assay, sensitivity, specificity,

241 PLR, DOR and AUC were higher for ELISPOT than for ELISA, but NLR was lower for ELISPOT

242 than for ELISA. Therefore, we cannot determine whether ELISPOT or ELISA shows greater overall

243 accuracy for diagnosing TP. This requires larger studies that compare the two types of IGRAs in

244 parallel.

The reliability of meta-analysis in general is limited by the methodological quality and heterogeneity

246 of included studies (Petitti DB, 2001). Quality scoring was compiled for every study on the basis of

247 title, introduction, methods, results and discussion. When a criterion was fulfilled, a score of 1 was

248 given, 0 if a criterion was unclear, and -1 if a criterion was not achieved. Quality of study can be

249 interpreted into different scores by the use of QUADAS, thus, easy to be carried out and compared.

250 Overall the quality of study design and reporting diagnostic accuracy of most studies were good to a

251 certain extent and five studies had a higher QUADAS score ( $\geq 11)$. IGRA performance was similar in

252 higher-quality studies (QUADAS $\geq 11$ ) and lower-quality ones. Pleural IGRA studies showed 
253 significant heterogeneity in meta-analyses of sensitivity, specificity, PLR, NLR and DOR. Whether the

254 study used ELISPOT or ELISA significantly affected the diagnostic accuracy of both pleural and blood

255 IGRAs. We also found that whether a study was performed in an area of low or high tuberculosis

256 incidence significantly affected the accuracy of blood IGRA, but not of pleural IGRA. A previous

257 study concluded that IGRA was more sensitive and specific than conventional methods in areas of high

258 tuberculosis prevalence (Gao Y et al., 2012). This contrasts with studies in low-incidence areas

259 showing that pleural fluid T-cells in pleural fluid respond to stimulation with ESAT-6 and CFP-10 are

260 significantly more than do to T-cells in peripheral blood (Ariga $\mathrm{H}$ et al., 2007; Losi M et al., 2007),

261 perhaps reflecting the fact that most patients in such areas are immunocompetent. Our observation of a

262 differential effect of study area on the two types of IGRAs may reflect country biases in the studies

263 examining each type of IGRA. Future studies should address this question in detail.

264 Theoretically, tuberculosis antigen-specific responses like the one measured by IGRA should allow

265 clinicians to distinguish PE from alternative diagnosis and provide greater discriminatory value than

266 non-specific inflammatory biomarkers such as unstimulated IFN- $\gamma$ or adenosine deaminase (ADA).

267 However, comparing our findings with those of previous meta-analyses (Zhou Q et al., 2011; Liang QL

268 et al., 2008) suggests that IGRA has lower overall accuracy than either IFN- $\gamma$ or ADA for diagnosing

269 TP. In fact, one study found that combining ADA and IFN- $\gamma$ to diagnose TP led to $100 \%$ specificity

270 (Keng LT et al., 2013). The authors of that study were unsure why IFN- $\gamma$ and ADA perform better than

271 IGRA. Future studies should investigate this question.

272 Some limitations should be discussed in this meta-analysis. First, we included only 
273 studies published in PubMed and Embase, and we excluded abstracts, letters to the

274 editor and articles written in languages other than English. This may have led to

275 publication bias, which is indeed suggested by our funnel plots and Egger's test.

276 Second, only five of the 15 publications diagnosed TP based on bacteriological or

277 histological assessment, or on the gold standard combination of both (Wilkinson KA

278 et al., 2005; Ariga H et al., 2007; Eldin EN et al., 2012; Liu F et al., 2013; Gao Y et

279 al., 2012). The remaining 10 publications used a mixture of bacteriological,

280 histological or clinical assessment (Losi M et al., 2007; Baba K et al., 2008; Chegou

281 NN et al., 2008; Dheda K et al., 2009; Lee LN et al., 2009; Keng LT et al., 2013; Ates

282 G et al., 2011; Kang JY et al., 2012; Liao MF et al., 2014; Chung JH et al., 2011).

283 Third, the results of this meta-analysis may be less applicable to severely

284 immunocompromised subjects, since IGRA depends on host immunity and many

285 studies excluded indeterminate results from analysis. This may have led to systematic

286 error in some studies.

\section{Conclusion}

288 Our meta-analysis suggests that pleural IGRA shows much better diagnostic performance than blood 
289 IGRA. Pleural IGRA has potential for serving as a complementary method for diagnosing TP but that

290 its sub-optimal performance, cost and high turnaround time make it unsuitable as a stand-alone

291 diagnostic tool. Better tests for the diagnosis of TP are required.

292 Additional Information and Declarations

293 Acknowledgments

294 We are indebted to the authors of the primary studies included in this meta-analysis; without their

295 contributions, this work would not have been possible.

296 Conflict of interest

297 The authors declare that there is no conflict of interests.

298 Author contributions

299 C.S.P. and Y.C.S conceived the article and contributed equally to the systematic review, meta-analysis, 300 and manuscript writing. C.S.P. and P.W.T. analyzed the data. J.Z. contributed to reference collection

301 and data management. C.W. and M.F. contributed to manuscript writing. F.Q.W. is guarantor of the

302 manuscript and takes responsibility for the integrity of the work as a whole, from inception to

303 published article.

304 Funding

305 This work was supported by grants 81230001 and 81300032 from the National Natural Science 306 Foundation of China. 
319 Vidal R, de Gracia J, Ruiz J, Fite E, Monsó E, Martín N. 1986. Controlled study

320 of 637 patients with tuberculosis: Diagnosis and therapeutic results with 9- and

321 6-month regimens. Med Clin 87:368-370.

322 Corbett EL, Watt CJ, Walker N, Maher D, Williams BG, Raviglione MC, Dye C. 
2003. The growing burden of tuberculosis: global trends and interactions with the

HIV epidemic. Arch Intern Med 163:1009-1021.

Valdés L, Pose A, San José E, Martinez Va'zquez JM. 2003. Tuberculous pleural

effusions. Eur J Intern Med 14:77-88.

327 Lin MT, Wang JY, Yu CJ, Lee LN, Yang PC. 2009. Mycobacterium tuberculosis

328 and polymorphonuclear pleural effusion: incidence and clinical pointers. Respir Med

$329 \quad$ 103:820-826.

330 Escudero BC, García CM, Cuesta CB, Molinos ML, Rodríguez RS, González

331 PA, Martínez GJ. 1990. Cytologic and bacteriologic analysis of fluid and pleural

332 biopsy specimens with Cope's needle: study of 414 patients. Arch Intern Med 150:

333 1190-1194.

334 Valdés L, Alvarez D, San José E, Penela P, Valle JM, García-Pazos JM, Suárez J,

335 Pose A. 1998. Tuberculous pleurisy: a study of 254 patients. Arch Intern Med 158:

$336 \quad 2017-2021$.

337 Pérez RE, Jiménez CD. 2000. The use of adenosine deaminase and adenosine

338 deaminase isoenzymes in the diagnosis of tuberculous pleuritis. Curr Opin Pulm 
Med 6:259-266.

340 Lawrence JG. 2000. Targeted tuberculin testing and treatment of latent tuberculosis infection. $\mathrm{Am} J$

341 Respir Crit Care Med 161:221-247.

342 Stead WW, To T. 1987. The significance of the tuberculin skin test in elderly persons.

343 Ann Intern Med 107:837-842.

344 Liebeschuetz S, Bamber S, Ewer K, Deeks J, Pathan AA, Lalvani A. 2004.

345 Diagnosis of tuberculosis in South African children with a T-cell-based assay: a

346 prospective cohort study. Lancet 364:2196-2203.

347 North RJ, Jung YJ. 2004. Immunity to tuberculosis. Annu Rev Immunol 22:

$348 \quad 599-623$.

349 Sharma SK, Mitra DK, Balamurugan A, Pandey RM, Mehra NK. 2002.

350 Cytokine polarization in miliary and pleural tuberculosis. J Clin Immunol 22:

$351 \quad 345-352$.

352 Yamada Y, Nakamura A, Hosoda M, Kato T, Asano T, Tonegawa K, Itoh M.

353 2001. Cytokines in pleural liquid for diagnosis of tuberculous pleurisy. Respir Med

354 95:577-581. 
355 Lalvani A. 2007. Diagnosing tuberculosis infection in the 21st century: new tools to

356 tackle an old enemy. Chest 131:1898-1906.

357 Pai M, Zwerling A, Menzies D. 2008. Systematic review: T-cell-based assays for

358 the diagnosis of latent tuberculosis infection: an update. Ann Intern Med 149:177-184.

359 Zhou Q, Chen YQ, Qin SM, Tao XN, Xin JB, Shi HZ. 2011. Diagnostic accuracy

360 of T-cell interferon-gamma release assays in tuberculous pleurisy: A meta-analysis.

361 Respirology 16:473-480.

362 Hooper CE, Lee YC, Maskell NA. 2009. Interferon-gamma release assays for

363 the diagnosis of TB pleural effusions: hype or real hope? Curr Opin Pulm Med 15:358-365.

364 Whiting P, Rutjes AW, Reitsma JB, Bossuyt PM, Kleijnen J. 2003. The

365 development of QUADAS: a tool for the quality assessment of studies of diagnostic

366 accuracy included in systematic reviews. BMC Med Res Methodol 3:25.

367 Devillé WL, Buntinx F, Bouter LM, Montori VM, de Vet HC, van der Windt DA,

368 Bezemer PD. 2002. Conducting systematic reviews of diagnostic studies: didactic

369 guidelines. BMC Med Res Methodol 2:9.

370 Moses LE, Shapiro D, Littenberg B. 1993. Combining independent studies of a 
371 diagnostic test into a summary ROC curve: data analytic approaches and some

372 additional considerations. Stat Med 12:1293-1316.

373 Irwig L, Macaskill P, Glasziou P, Fahey M. 1995. Meta-analytic methods for

374 diagnostic test accuracy. J Clin Epidemiol 48:119-130.

375 Vamvakas EC. 1998. Meta-analyses of studies of the diagnostic accuracy of laboratory tests: a review

376 of the concepts and methods. Arch Pathol Lab Med

$377 \quad$ 122:675-686.

378 Shen YC, Liu MQ, Wan C, Chen L, Wang T, Wen FQ. 2012. Diagnostic

379 accuracy of vascular endothelial growth factor for malignant pleural effusion: A

380 meta-analysis. Exp Ther Med 3:1072-1076.

381 Wilkinson KA, Wilkinson RJ, Pathan A, Ewer K, Prakash M, Klenerman P,

382 Maskell N, Davies R, Pasvol G, Lalvani A. 2005. Ex vivo characterization of

383 early secretory antigenic target 6-specific $\mathrm{T}$ cells at sites of active disease in pleural

384 tuberculosis. Clin Infect Dis 40:184-187.

385 Ariga H, Kawabe Y, Nagai H, Kurashima A, Masuda K, Matsui H, Tamura A,

386 Nagayama N, Akagawa S, Machida K, Hebisawa A, Nakajima Y, Yotsumoto 
H, Mori T. 2007. Diagnosis of active tuberculous serositis by antigen-specific

388 interferon-gamma response of cavity fluid cells. Clin Infect Dis 45:1559-1567.

389 Losi M, Bossink A, Codecasa, Jafari C, Ernst M, Thijsen S, Cirillo D,

390 Ferrarese M, Greinert U, Fabbri LM, Richeldi L, Lange C. 2007. Use of a

391 T-cell Interferon gamma release assay for the diagnosis of tuberculous pleurisy.

392 Eur Respir J 30:1173-1179.

393 Baba K, Sørnes S, Hoosen AA, Lekabe JM, Mpe MJ, Langeland N,

394 Dyrhol-Riise AM. 2008. Evaluation of immune responses in HIV infected patients

395 with pleural tuberculosis by the QuantiFERONTB-Gold interferon-gamma assay.

396 BMC Infect Dis 8:35.

397 Chegou NN, Walzl G, Bolliger CT, Diacon AH, van den Heuvel MM. 2008.

398 Evaluation of adapted whole-blood interferon-gamma release assays for the

399 diagnosis of pleural tuberculosis. Respiration 76:131-138.

400 Dheda K, van Zyl-Smit RN, Sechi LA, Badri M, Meldau R, Meldau S, Symons

401 G, Semple PL, Maredza A, Dawson R, Wainwright H, Whitelaw A, Vallie Y,

402 Raubenheimer P, Bateman ED, Zumla A. 2009. Utility of quantitative T-cell 
403 responses versus unstimulated interferon- $\gamma$ for the diagnosis of pleural tuberculosis.

404 Eur Respir J 34:1118-1126.

405 Lee LN, Chou CH, Wang JY, Hsu HL, Tsai TH, Jan IS, Hsueh PR, Yang PC.

406 2009. Enzyme-linked immunospot assay for interferon-g in the diagnosis of

407 tuberculous pleurisy. Clin Microbiol Infect 15:173-179.

408 Keng LT, Shu CC, Chen JY, Liang SK, Lin CK, Chang LY, Chang CH, Wang

409 JY, Yu CJ, Lee LN. 2013. Evaluating pleural ADA, ADA 2, IFN- $\gamma$ and IGRA for

410 diagnosing tuberculous pleurisy. Infect 67:294-302.

411 Ates G, Yildiz T, Ortakoylu MG, Ozekinci T, Erturk B, Akyildiz L, Caglar E.

412 2011. Adapted $T$ cell interferon-gamma release assay for the diagnosis of pleural

413 tuberculosis. Respiration 82:351-357.

414 Eldin EN, Omar A, Khairy M, Mekawy AH, Ghanem MK. 2012. Diagnostic

415 value of exvivo pleural fluid interferon-gamma versus adapted whole-blood

416 quantiferon-TB gold in tube assays in tuberculous pleural effusion. Ann Thorac Med

$417 \quad 7: 220-225$.

418 Kang JY, Rhee CK, Kang NH, Kim JS, Yoon HK, Song JS. 2012. Clinical Utility 
419 of Two Interferon-gamma Release Assays on PF for the Diagnosis of Tuberculous

420 Pleurisy. Tuberc Respir Dis 73:143-150.

421 Liu F, Gao M, Zhang X, Du F, Jia H, Yang X, Wang Z, Zhang L, Ma L, Wu X,

422 Xie L, Zhang Z. 2013. Interferon-Gamma Release Assay Performance of Pleural

423 Fluid and Peripheral Blood in Pleural Tuberculosis. PLoS ONE 8:e0083857.

424 Liao MF, Yang Q, Zhang J, Zhang M, Deng Q, Liu H, Graner MW, Kornfeld H Zhou B, Chen X.

425 2014. Interferon-gamma immunospot assay of pleural effusion mononuclear cells for diagnosis of

426 tuberculous pleurisy. Clin Vaccine Immunol 21:

$427 \quad 347-353$.

428 Chung JH, Han CH, Kim CJ, Lee SM. 2011. Clinical utility of QuantiFERON-TB

429 GOLD In-Tube and tuberculin skin test in patients with tuberculous pleural effusions. Diagn Microbiol

$430 \quad$ Infect Dis 71:263-266.

431 Gao Y, Ou Q, Huang F, Wang S, Shen L, Shen Y, Wu J, Zheng J, Weng X, Zhang

432 W, Shao L. 2012. Improved diagnostic power by combined interferon-gamma release

433 assay and nested-PCR in tuberculous pleurisy in high tuberculosis prevalence area.

434 FEMS Immunol Med Microbiol 66:393-398. 
435 Jones CM, Athanasiou T. 2005. Summary receiver operating characteristic curve analysis techniques 436 in the evaluation of diagnostic tests. Ann Thorac Surg 79:16-20.

437 Diel R, Goletti D, Ferrara G, Bothamley G, Cirillo D, Kampmann B, Lange C, Losi M, Markova

438 R, Migliori GB, Nienhaus A, Ruhwald M, Wagner D, Zellweger JP, Huitric E, Sandgren A,

439 Manissero D. 2011. Interferon-gamma release assays for the diagnosis of latent Mycobacterium

440 tuberculosis infection: a systematic review and meta-analysis. Eur Respir J 37:88-99.

441 Sester M, Sotgiu G, Lange C, Giehl C, Girardi E, Migliori GB, Bossink A, Dheda K, Diel R,

442 Dominguez J, Lipman M, Nemeth J, Ravn P, Winkler S, Huitric E, Sandgren A, Manissero D.

443 2011. Interferon-gamma release assays for the diagnosis of active tuberculosis: a systematic review and 444 meta-analysis. Eur Respir J 37: 100-111.

445 Petitti DB. 2001. Approaches to heterogeneity in meta-analysis. Stat Med 20:

$446 \quad 3625-3633$.

447 Liang QL, Shi HZ, Wang K, Qin SM, Qin XJ. 2008. Diagnostic precision of

448 adenosine deaminase in tuberculous pleurisy: a meta-analysis. Respir Med

$449 \quad$ 102:744-754.

450 
1

Flow diagram of included and excluded studies

Figure1-Flow diagram of included and excluded studies

124 Records identified from PubMed, Embase after search terms selected
Studies excluded for: not relevant to tuberculous pleural effusion ( $n=38$ ); not diagnostic test $(n=27)$; not relevant to interferon gamma release assay $(n=52)$; case report $(n=4)$.

6 potential records concerning the current topic for full-text review

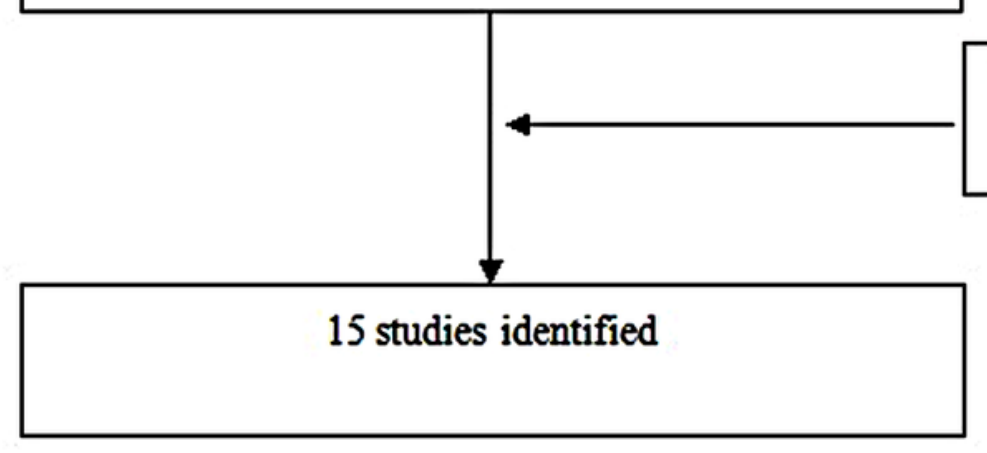

9 studies included: using Related-articles function 
Forest plot showing estimates of sensitivity and specificity

Figure 2 - Forest plot showing estimates of sensitivity and specificity for T-cell interferon-gamma assays in pleural fluid (A) and peripheral blood(B). Point estimates of sensitivity and specificity from each study are shown as solid circles. Error bars indicate $95 \% \mathrm{Cl}$.

A
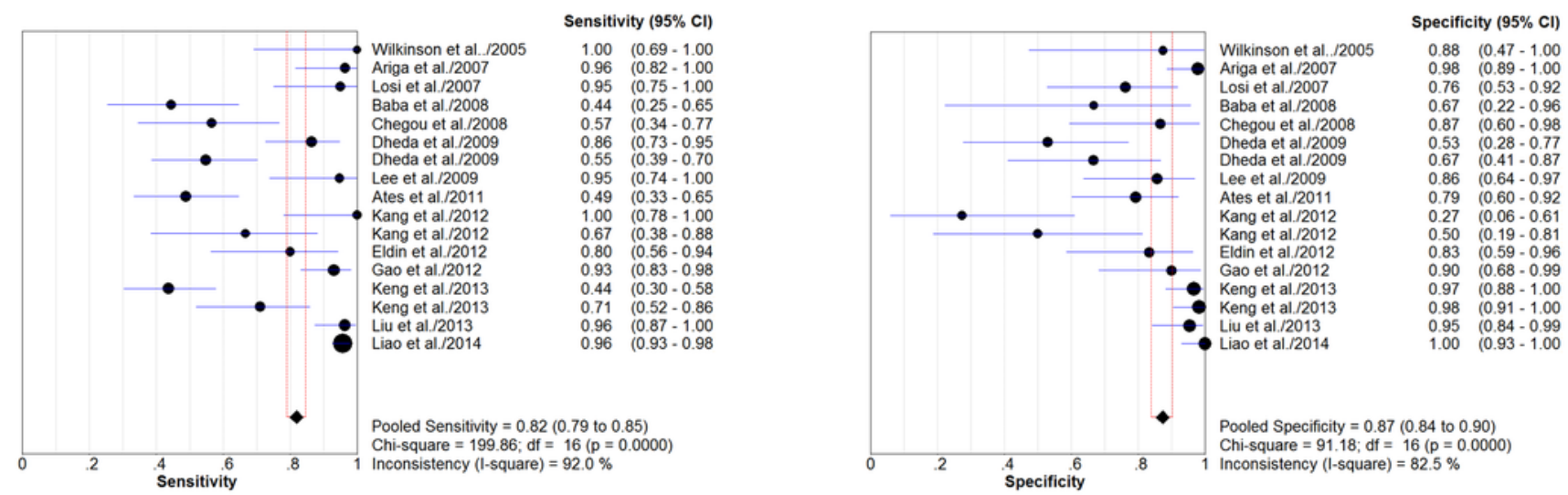

B
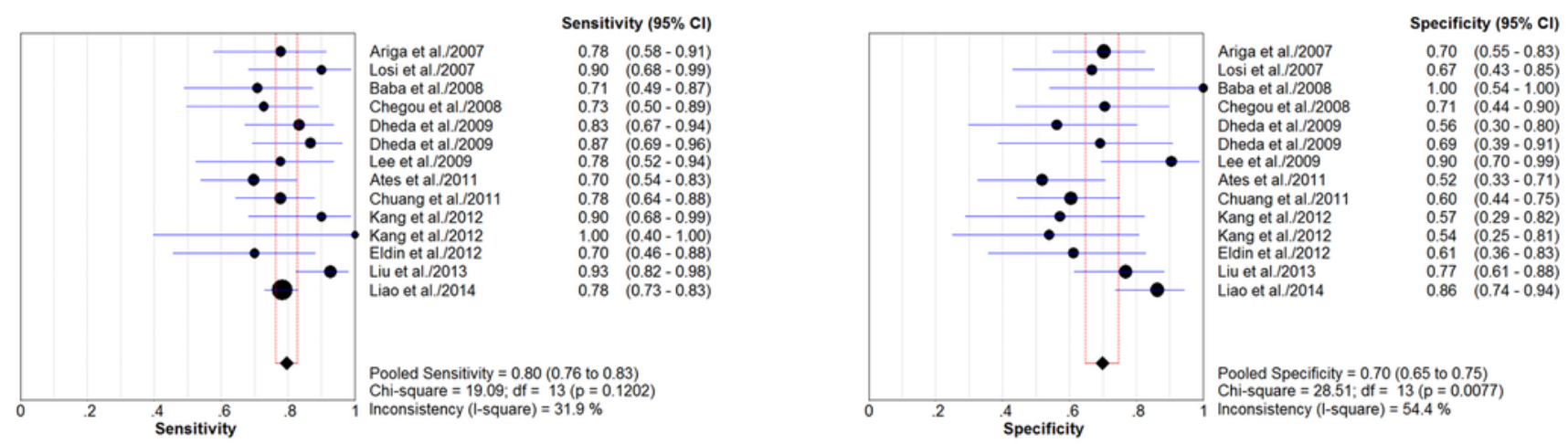


\section{3}

Summary receiver operating characteristic curves

Figure 3 - Summary receiver operating characteristic (SROC) curves for T-cell interferon-gamma assays in pleural fluid (A) and peripheral blood (B). Solid circles represent each study included in the meta-analysis, with circle size representing the sample size in each study. The regression SROC curves summarize the overall diagnostic accuracy. 
A

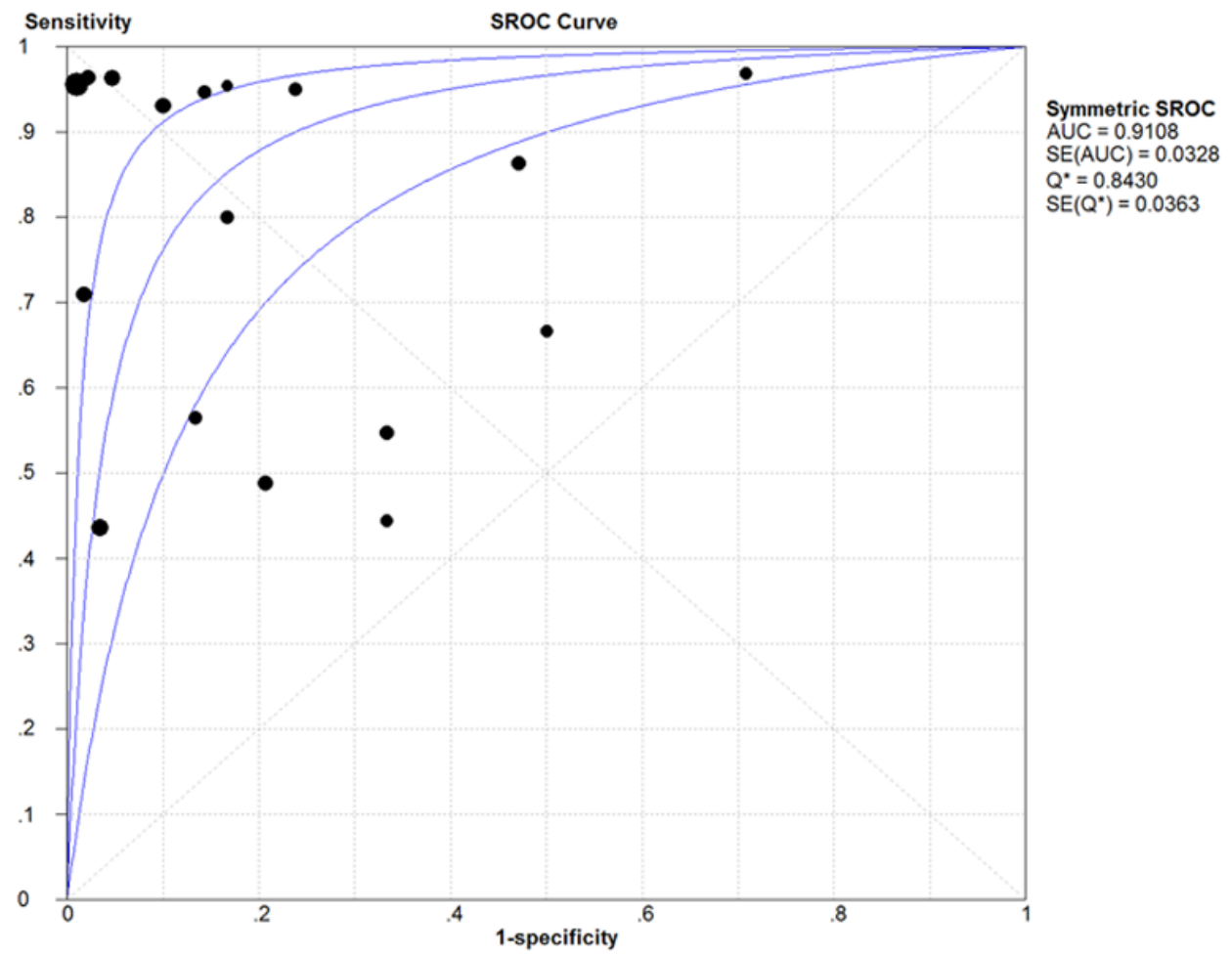

B

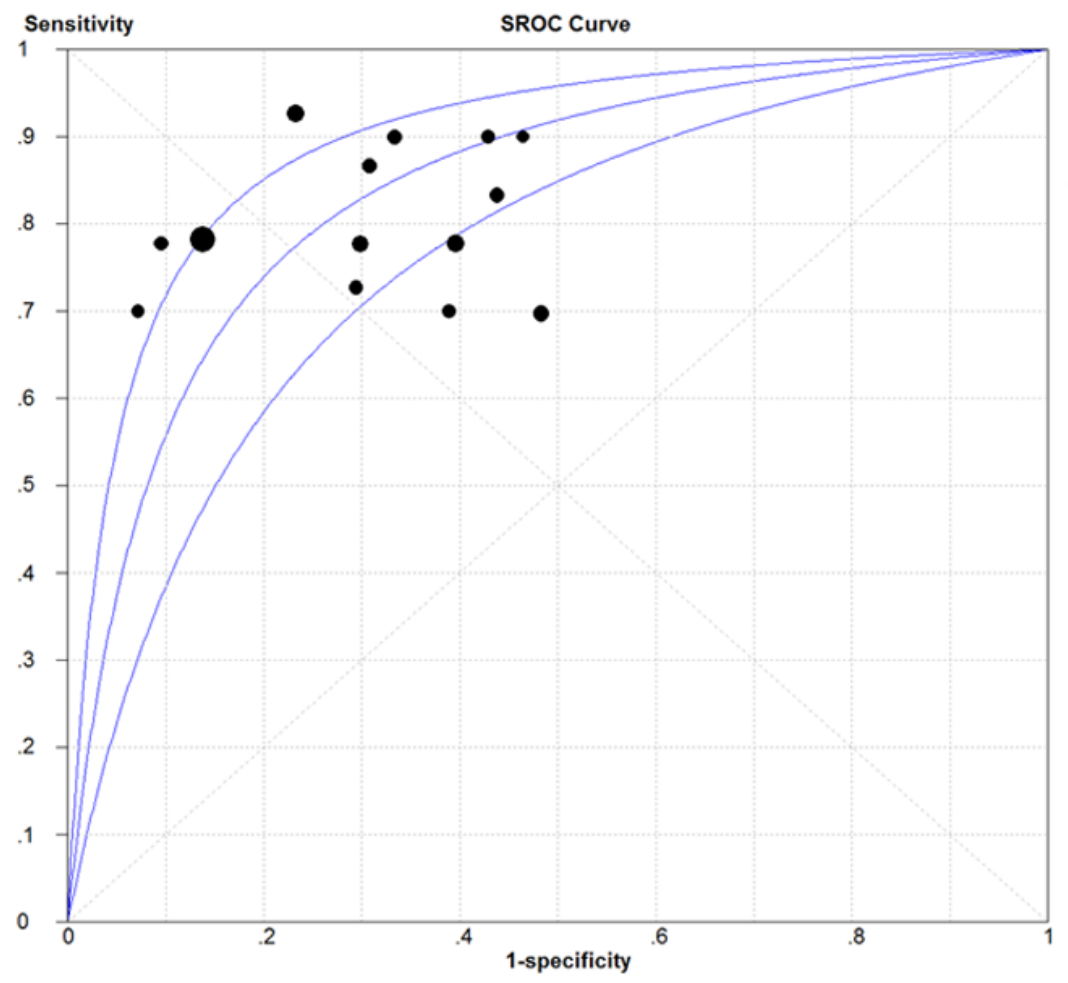

Symmetric SROC AUC $=0.8392$ $\mathrm{SE}(\mathrm{AUC})=0.0307$ $Q^{*}=0.7711$

$\mathrm{SE}\left(\mathrm{Q}^{*}\right)=0.0284$ 


\section{4}

Funnel graph for assessing risk of publication bias

Figure 4- Funnel graph for assessing risk of publication bias in studies of T-cell interferon-gamma release assays in pleural fluid (A) and peripheral blood (B). The funnel graph plots the log of the diagnostic odds ratio (DOR) against the standard error of the log of the DOR (an indicator of sample size). Solid circles represent each study inthemetaanalysis. The central lines indicate the summary DOR. 
A

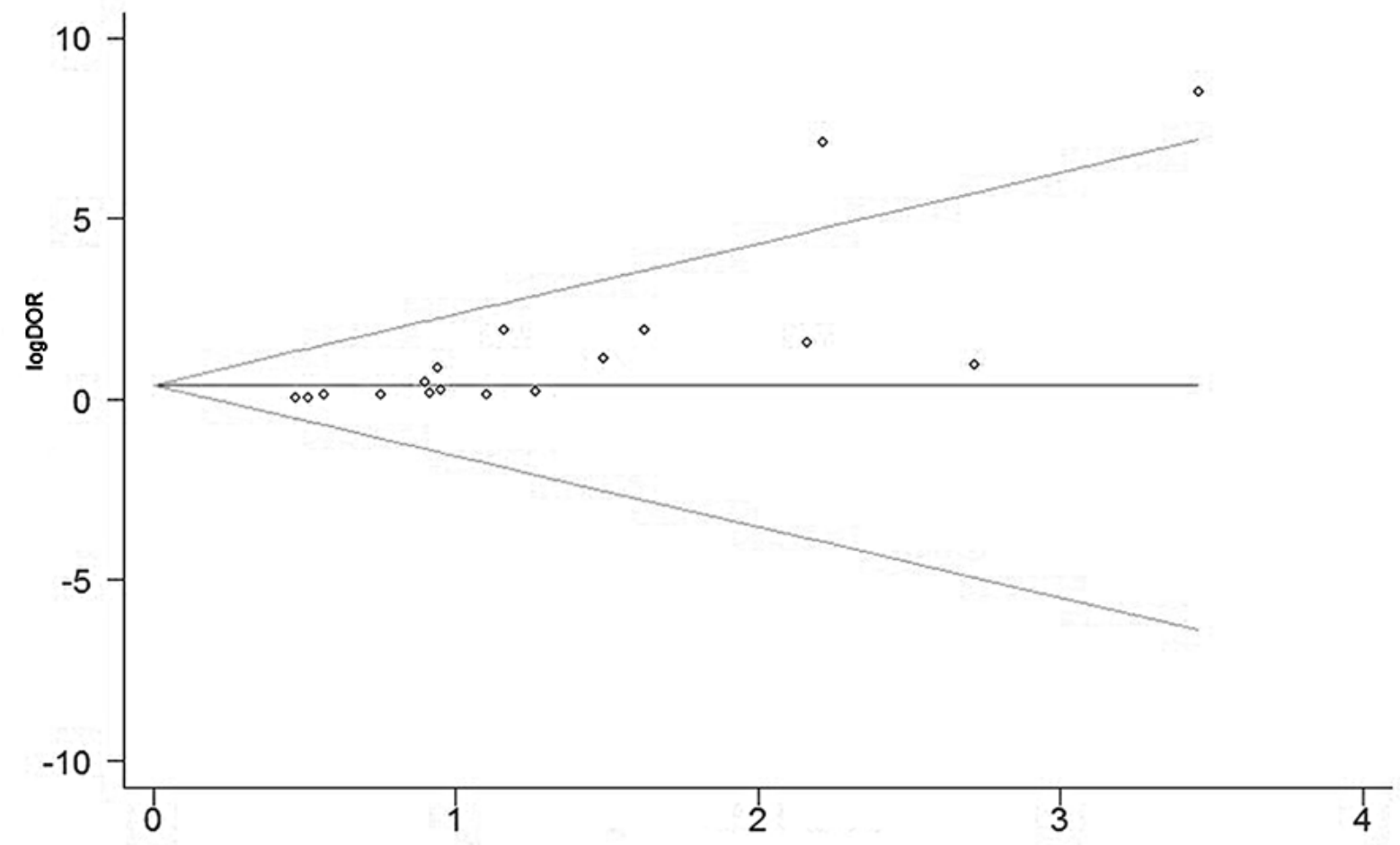

s.e. of: $\log D O R$

B

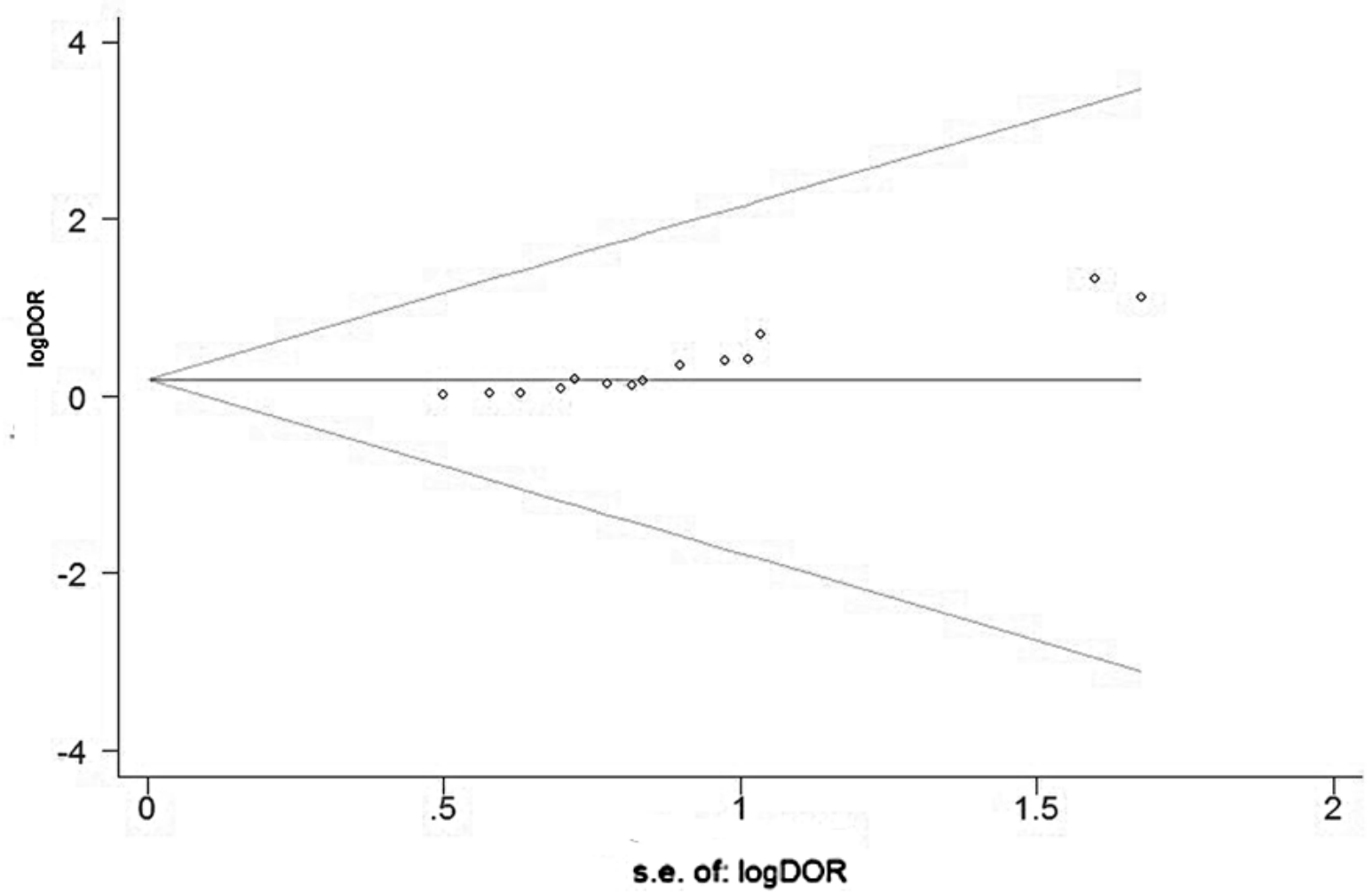

Peer] reviewing PDF | (2015:01:3825:2:0:NEW 18 Apr 2015) 
Table $\mathbf{1}$ (on next page)

Key characteristics of studies

Table 1: Key characteristics of the studies included in the meta-analysis 
2 Table 1: Key characteristics of the studies included in the meta-analysis

\begin{tabular}{|c|c|c|c|c|c|c|c|c|}
\hline \multirow[t]{2}{*}{ First Author } & \multirow[t]{2}{*}{ Settings } & \multirow{2}{*}{$\begin{array}{l}I G R A \\
\text { method }\end{array}$} & \multirow[t]{2}{*}{ Samples } & \multicolumn{4}{|c|}{ Test results } & \multirow{2}{*}{$\begin{array}{l}\text { QUADAS } \\
\text { score }\end{array}$} \\
\hline & & & & $\mathrm{TP}$ & FP & FN & $\mathrm{TN}$ & \\
\hline \multirow[t]{2}{*}{ Wilkinson } & UK & ELISPOT & $\mathrm{PE}$ & 10 & 1 & 0 & 7 & 10 \\
\hline & & & Blood & 10 & - & 0 & - & \\
\hline \multirow[t]{2}{*}{ Ariga } & Japan & ELISA & $\mathrm{PE}$ & 27 & 1 & 1 & 46 & 11 \\
\hline & & & Blood & 21 & 14 & 6 & 33 & \\
\hline \multirow[t]{3}{*}{ Losi } & Italy, & ELISPOT & $\mathrm{PE}$ & 19 & 5 & 1 & 16 & 10 \\
\hline & Germany, & & Blood & 18 & 7 & 2 & 14 & \\
\hline & Netherlands & & & & & & & \\
\hline \multirow[t]{2}{*}{ Baba } & South & ELISA & $\mathrm{PE}$ & 12 & 2 & 15 & 4 & 10 \\
\hline & Africa & & Blood & 17 & 0 & 7 & 6 & \\
\hline \multirow[t]{2}{*}{ Chegou } & South & ELISA & PE & 13 & 2 & 10 & 13 & 13 \\
\hline & Africa & & Blood & 16 & 5 & 6 & 12 & \\
\hline \multirow[t]{4}{*}{ Dheda } & South & ELISPOT & $\mathrm{PE}$ & 38 & 8 & 6 & 9 & 11 \\
\hline & Africa & & Blood & 30 & 7 & 6 & 9 & \\
\hline & & ELISA & $\mathrm{PE}$ & 23 & 6 & 19 & 12 & \\
\hline & & & Blood & 26 & 4 & 4 & 9 & \\
\hline \multirow[t]{2}{*}{ Lee } & Taiwan & ELISPOT & $\mathrm{PE}$ & 18 & 3 & 1 & 18 & 9 \\
\hline & & & Blood & 14 & 2 & 4 & 19 & \\
\hline \multirow[t]{2}{*}{ Ates } & Turkey & ELISA & $\mathrm{PE}$ & 21 & 6 & 22 & 23 & 11 \\
\hline & & & Blood & 30 & 14 & 13 & 15 & \\
\hline Chuang & South & ELISA & Blood & 42 & 17 & 12 & 26 & 8 \\
\hline
\end{tabular}




\begin{tabular}{|c|c|c|c|c|c|c|c|c|}
\hline & Korea & & & & & & & \\
\hline \multirow[t]{4}{*}{ Kang } & South & ELISPOT & $\mathrm{PE}$ & 15 & 8 & 0 & 3 & 9 \\
\hline & Korea & & Blood & 18 & 6 & 2 & 8 & \\
\hline & & ELISA & $\mathrm{PE}$ & 10 & 5 & 5 & 5 & \\
\hline & & & Blood & 4 & 6 & 0 & 7 & \\
\hline \multirow[t]{2}{*}{ Eldin } & Egypt & ELISA & $\mathrm{PE}$ & 16 & 3 & 4 & 15 & 7 \\
\hline & & & Blood & 14 & 7 & 6 & 11 & \\
\hline Gao & China & ELISA & $\mathrm{PE}$ & 54 & 2 & 4 & 18 & 8 \\
\hline \multirow[t]{2}{*}{ Keng } & Taiwan & ELISA & $\mathrm{PE}$ & 24 & 2 & 31 & 57 & 8 \\
\hline & & & $\mathrm{PE}$ & 22 & 1 & 9 & 56 & \\
\hline \multirow[t]{2}{*}{ Liu } & China & ELISPOT & $\mathrm{PE}$ & 53 & 2 & 2 & 41 & 9 \\
\hline & & & Blood & 51 & 10 & 4 & 33 & \\
\hline \multirow[t]{2}{*}{ Liao } & China & ELISPOT & $\mathrm{PE}$ & 269 & 0 & 12 & 51 & 8 \\
\hline & & & Blood & 220 & 7 & 61 & 44 & \\
\hline
\end{tabular}

3 ELISPOT, enzyme-linked immunosorbent spot; ELISA, enzyme-linked immunosorbent assay; FN, false 4 negative; FP, false positive; IGRA, T-cell interferon- $\gamma$ release assay; PE, pleural effusion; QUADAS, quality 5 assessment for studies of diagnostic accuracy; TN, true negative; TP, true positive. 
Table 2 (on next page)

Pooled results for accuracy

Table 2: Pooled results for accuracy of interferon-gamma assays to diagnose tuberculous pleurisy 


\begin{tabular}{|c|c|c|c|c|c|c|}
\hline \multirow[t]{2}{*}{ ? } & \multicolumn{3}{|c|}{ Pleural effusion } & \multicolumn{3}{|c|}{ Blood } \\
\hline & Total & ELISPOT & ELISA & Total & ELISPOT & ELISA \\
\hline number of study & 17 & 7 & 10 & 14 & 6 & 8 \\
\hline sensitivity $(95 \% \mathrm{CI})$ & $0.82(0.79-0.85)$ & $0.95(0.93-0.97)$ & $0.65(0.60-0.70)$ & $0.80(0.76-0.83)$ & $0.82(0.78-0.85)$ & $0.76(0.70-0.81)$ \\
\hline Heterogeneity*(P) & $199.86(<0.001)$ & 7.93(0.24) & $67.65(<0.001)$ & $19.09(0.12)$ & $9.99(0.075)$ & $6.17(0.52)$ \\
\hline specificity $(95 \% \mathrm{CI})$ & $0.87(0.84-0.9)$ & $0.84(0.78-0.89)$ & $0.89(0.85-0.93)$ & $0.70(0.65-0.75)$ & $0.77(0.69-0.83)$ & $0.64(0.57-0.71)$ \\
\hline Heterogeneity $(\mathrm{P})$ & $91.18(<0.001)$ & $50.63(<0.001)$ & $38.25(<0.001)$ & $28.52(0.008)$ & $12.57(0.028)$ & $9.34(0.23)$ \\
\hline $\operatorname{PLR}(95 \% \mathrm{CI})$ & $4.94(2.60-9.39)$ & $5.62(1.65-19.14)$ & $4.6(2.16-9.82)$ & $2.48(1.95-3.17)$ & $3.21(2.09-4.94)$ & $2.00(1.63-2.45)$ \\
\hline Heterogeneity $(\mathrm{P})$ & $129.36(<0.001)$ & $94.35(<0.001)$ & $42.71(<0.001)$ & $26.57(0.014)$ & $12.18(0.03)$ & $6.13(0.525)$ \\
\hline $\operatorname{NLR}(95 \% \mathrm{CI})$ & $0.22(0.13-0.38)$ & $0.08(0.04-0.16)$ & $0.41(0.27-0.62)$ & $0.30(0.24-0.37)$ & $0.22(0.16-0.31)$ & $0.38(0.30-0.50)$ \\
\hline Heterogeneity $(\mathrm{P})$ & $180.23(<0.001)$ & $12.33(0.06)$ & $48.66(<0.001)$ & $18.02(0.16)$ & $6.13(0.294)$ & $5.23(0.632)$ \\
\hline PPV(95\% CI) & $0.91(0.85-0.96)$ & $0.87(0.8-1.03)$ & $0.96(0.68-1.32)$ & $0.79(0.60-0.87)$ & $0.74(0.64-0.84)$ & $0.84(0.75-1.19)$ \\
\hline Heterogeneity $(\mathrm{P})$ & $132(<0.001)$ & $46.52(0.03)$ & $61.25(<0.001)$ & $4.27(0.09)$ & $6.79(1.22)$ & $5.76(0.46)$ \\
\hline $\mathrm{NPV}(95 \% \mathrm{CI})$ & $0.79(0.71-0.85)$ & $0.75(0.65-0.87)$ & $0.84(0.7-1.41)$ & $0.75(0.62-0.83)$ & $0.72(0.58-0.81)$ & $0.76(0.65-0.88)$ \\
\hline Heterogeneity $(\mathrm{P})$ & $157(<0.001)$ & $9.68(<0.001)$ & $16.9(<0.001)$ & $4.54(0.07)$ & $7.01(1.13)$ & $11.53(0.06)$ \\
\hline $\operatorname{DOR}(95 \% \mathrm{CI})$ & $28.37(10.53-76.4)$ & $88.85(16.10-490.43)$ & $14.10(4.56-43.54)$ & $9.96(6.02-16.48)$ & $19.82(11.67-33.66)$ & $5.46(3.46-8.61)$ \\
\hline Heterogeneity $(\mathrm{P})$ & $81.01(<0.001)$ & $23.47(0.001)$ & $43.65(<0.001)$ & $24.44(0.03)$ & $4.93(0.43)$ & $6.38(0.496)$ \\
\hline AUC(SEM) & $0.91(0.03)$ & $0.98(0.01)$ & $0.84(0.08)$ & $0.84(0.03)$ & $0.89(0.02)$ & $0.78(0.04)$ \\
\hline
\end{tabular}

$5 * \mathrm{Q}$ value.

6 AUC, area under the curve; DOR, diagnostic odds ratio; ELISPOT, enzyme-linked immunosorbent 7 spot; ELISA, enzyme-linked immunosorbent assay; NLR, negative likelihood ratio; PLR, positive 8 likelihood ratio; PPV, positive predictive value; NPV, negative predictive value. 
Table 3(on next page)

Weighted meta-regression

Table3: Weighted meta-regression to assess the effects of study setting, IGRA method and study quality on diagnostic accuracy of IGRA 
2 Table 3: Weighted meta-regression to assess the effects of study setting, IGRA method and study 3 quality on diagnostic accuracy of IGRA

\begin{tabular}{cccc}
\hline $\begin{array}{c}\text { Covariate } \\
\text { Number of } \\
\text { studies }\end{array}$ & Coefficient & RDOR(95\%CI) & $P$-value \\
\hline
\end{tabular}

Pleural effusion

QUADAS score

$\begin{array}{lllll}\geq 11 & 5 & -1.44 & 0.24(0.02-2.70) & 0.225\end{array}$

$<11 \quad 12$

Setting

$\begin{array}{lllll}\text { Area with low TB incidence } & 7 & 0.36 & 1.44(0.10-21.14) & 0.777\end{array}$

Area with high TB incidence $\quad 10$

Method

ELISPOT

7

$-3.17$

$0.04(0.00-0.60)$

0.023

ELISA

10

Peripheral blood?

QUADAS score

$\geq 11$

5

$-0.81$

$0.45(0.15-1.35)$

0.137

$<11$

9

Setting??]

Area with low TB incidence

7

1.12

$3.06(1.16-8.10)$

0.028

Area with high TB incidence

7

Method?

ELISPOT

6

$-1.26$

$0.28(0.13-0.62)$

0.0048 
ELISA 8

4 RDOR, relative diagnostic odds ratio; QUADAS, quality assessment for studies of diagnostic accuracy; TB, 5 tuberculosis; ELISA, enzyme-linked immunosorbent assay; ELISPOT, enzyme-linked immunosorbent spot. 